\title{
Colonic transit time and pressure based on Bernoulli's principle
}

\author{
Yoshiharu Uno \\ Office Uno Column, Yota, Onoe-Cho, \\ Kakogawa, Japan
}

This article was published in the following Dove Press journal: Clinical and Experimental Gastroenterology

Purpose: Variations in the caliber of human large intestinal tract causes changes in pressure and the velocity of its contents, depending on flow volume, gravity, and density, which are all variables of Bernoulli's principle. Therefore, it was hypothesized that constipation and diarrhea can occur due to changes in the colonic transit time (CTT), according to Bernoulli's principle. In addition, it was hypothesized that high amplitude peristaltic contractions (HAPC), which are considered to be involved in defecation in healthy subjects, occur because of cecum pressure based on Bernoulli's principle.

Methods: A virtual healthy model (VHM), a virtual constipation model and a virtual diarrhea model were set up. For each model, the CTT was decided according to the length of each part of the colon, and then calculating the velocity due to the cecum inflow volume. In the VHM, the pressure change was calculated, then its consistency with HAPC was verified.

Results: The CTT changed according to the difference between the cecum inflow volume and the caliber of the intestinal tract, and was inversely proportional to the cecum inflow volume. Compared with VHM, the CTT was prolonged in the virtual constipation model, and shortened in the virtual diarrhea model. The calculated pressure of the VHM and the gradient of the interlocked graph were similar to that of HAPC.

Conclusion: The CTT and HAPC can be explained by Bernoulli's principle, and constipation and diarrhea may be fundamentally influenced by flow dynamics.

Keywords: colonic transit time, Bernoulli's principle, constipation, diarrhea, high amplitude peristaltic contractions

\section{Introduction}

The colonic transit time (CTT) is an important variable in constipation and diarrhea. ${ }^{1}$ High amplitude peristaltic contractions (HAPC) are believed to be an important factor that can change the CTT. ${ }^{2}$ However, HAPC do not directly involve strong spontaneous contraction of smooth muscle, but indirectly implies high pressure conduction in the lumen. In practice, experiments involving HAPC of human colon in vivo have been performed by measuring the pressure increase after expansion of a balloon placed in a liquid-filled lumen. ${ }^{3}$ Therefore, it is undeniable that HAPC is not only a neurological reflex caused by the pacemaker's spontaneous contraction and colonic distention, but also the continuous conduction of pressure generated by increasing flow volume. Studies with manometers have discussed increasing pressure by contractility of the intestines, but endoscopic research has shown that the pressure increases when the lumen expands. ${ }^{4}$ Namely, it is possible that HAPC is not only a continuous conduction

Correspondence: Yoshiharu Uno Office Uno Column, Yoshiharu Uno: 419-2 Yota, Onoe-Cho, Kakogawa, Hyogo 675-0025, Japan

Tel +81794394697

Fax +8I 794394697

Email yoshiharu333@hotmail.com 
of smooth muscle contraction, but is also a flow dynamic pressure transfer phenomenon. It is also known that amplitude of antegrade propagating pressure decreases in the ascending colon and increases from the descending colon to the sigmoid colon, ${ }^{5}$ and net hourly forward progress was greater in the left than right colon. ${ }^{6}$ The fact that HAPC is prone to awakening upon, and after, meals can be explained by an increase in the velocity of the colonic contents due to gravity.

The large intestine differs in caliber between the proximal and distal regions, and has 7 sphincters. ${ }^{7}$ In anatomical orbit studies, ${ }^{6,8}$ the colon transit markers have shown a tendency to stagnate just before the sphincters. This fact suggests that the low-velocity in the expanded part of the colon was caused by contraction of the distal section of the colon. The variations in CTT with inflow volume can be explained by the fact that bowel movement can be induced instantaneously with an antegrade continence enema (ACE), which involves injecting a large amount of liquid into the cecum from the cecostomy tube. ${ }^{9}$ Pressure, velocity, gravity, inflow volume, and caliber changes in the continuous lumen are all variables of Bernoulli's principle, and equations of continuity. With these backgrounds, changes in transit time of the colon due to changes in the variables of Bernoulli's principle were calculated. Specifically, pressure changes obtained from calculations were compared with HAPC, and the relationship between the changes in variables, and constipation and diarrhea, were further investigated.

\section{Methods}

\section{Two hypotheses}

- The CTT depends on caliber, cecum inflow volume, fluid density, fluid velocity, and gravity, and constipation and diarrhea are determined by Bernoulli's principle.

- In the normal form of the large intestine, the change in pressure obtained by inflow volume is similar to HAPC.

\section{Basic formula for the research hypothesis} Bernoulli's principle

$\frac{1}{2} \mathrm{v}^{2}+\frac{P}{\rho}+\mathrm{gh}=$ Constant

$\rho=$ density of fluid, $\mathrm{v}=$ velocity of the fluid, $\mathrm{g}=$ gravitational acceleration, $\mathrm{h}=$ height, $P=$ pressure

Equation of continuity

$Q=A_{1} \mathrm{v}_{1}=A_{2} \mathrm{v}_{2}$

$A=$ cross-sectional area, $Q=$ flow volume

\section{CTT calculation method}

CTT was calculated using Bernoulli's principle and the equation of continuity, as shown in Figure 1.

\section{Setting the conditions for testing the hypothesis:}

1. Ignore the surface tension and compliance of the expanded intestinal wall.

\section{Bernoulli's principle}

$$
\frac{1}{2} v^{2}+\frac{P}{\rho}+g h=\text { Constant }
$$

$$
\because \frac{\mathrm{V}_{1}{ }^{2}}{2}+\frac{\mathrm{P}_{1}}{\rho}+\mathrm{gh}_{1}=\frac{\mathrm{V}_{2}^{2}}{2}+\frac{\mathrm{P}_{2}}{\rho}+\mathrm{gh}_{2}
$$

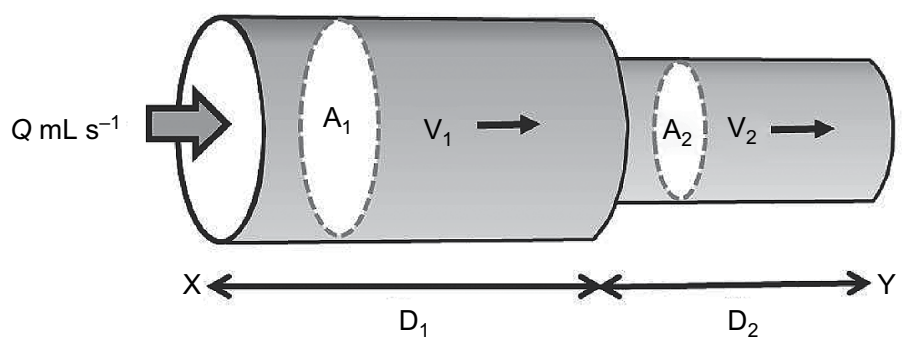

$$
\text { Transit time (between } X \text { and } Y \text { ) }=\frac{D_{1}}{V_{1}}+\frac{D_{2}}{V_{2}}
$$

Equation of continuity $Q=A_{1} V_{1}=A_{2} V_{2}$

Figure I CTT calculation method using Bernoulli's principle.

Notes: The transit time can be calculated from the inflow volume into the lumen, the diameter, and the length of the lumen.

Abbreviation: CTT, colonic transit time. 
2. Ignore friction by feces and tribology caused by mucus.

3. Ignore haustra and semilunar fold.

4. The caliber of the normal model, constipation model, and diarrhea model were set according to analysis of measured values, and figures based on past literature. ${ }^{1,10-14}$

\section{Hypothesis verification method}

Does the CTT depend on caliber, cecum inflow volume, fluid density, fluid velocity and gravity; and are constipation and diarrhea determined by Bernoulli's principle?

The hypothesis was verified by calculating the velocity and CTT under the following conditions:

\section{Virtual healthy model (VHM)}

The caliber and length of a normal lumen and sphincter were set (Figure 2A). The caliber of the 7 lumen sphincters (Busi ring, Hirsch ring, Cannon ring, Payr-Strauss ring, Balli ring, Moultier ring, Rossi ring) were set to $1 \mathrm{~cm}$, and their length was set to $2 \mathrm{~cm}$. From the cecum to the ascending colon, the cecum radius was $4 \mathrm{~cm}$ and the ascending colon radius was set to $3.25 \mathrm{~cm}$. The negative influence by positional energy was calculated by gravity and height, and the stool density was set to $1.0 \mathrm{~g} \mathrm{~cm}^{-3}$. For the transverse colon, the radius was set to $2.7 \mathrm{~cm}$, the stool density was set at $1.3 \mathrm{~g} \mathrm{~cm}^{-3}$, and the positional energy involvement was excluded. From the descending colon to the sigmoid colon, the radius of the sigmoid colon from the descending colon was set to 1.5 $\mathrm{cm}$, the stool density was set at $1.3 \mathrm{~g} \mathrm{~cm}^{-3}$, and the positive influence by positional energy was calculated by gravity and height. For the sigmoid colon, the radius was set to $1.5 \mathrm{~cm}$, the stool density was set to $1.3 \mathrm{~g} \mathrm{~cm}^{-3}$, and the positional energy involvement was excluded. From the sigmoid colon to the rectum, the radius of the rectum was set to $2.25 \mathrm{~cm}$, the stool density was set to $1.3 \mathrm{~g} \mathrm{~cm}^{-3}$, and the positive influence by positional energy was calculated by gravity and height.

The CTT was calculated by adding the transit times in each segment from the velocity obtained by the above.

\section{Virtual constipation model (VCM)}

The VCM was set primarily with reference to constipation with megacolon (Figure 2B). ${ }^{1,10-13}$ The wide caliber, without the 7 sphincters, was set as follows: the radius of the cecum was set to $6 \mathrm{~cm}$; the radius of the ascending colon was set to 4 $\mathrm{cm}$; the radius of the transverse colon, descending colon, and sigmoid colon were set to $3.25 \mathrm{~cm}$; the radius of the rectum was set to $4.5 \mathrm{~cm}$. Gravity and density were assumed to be equal to that of the VHM.

\section{Virtual diarrhea model (VDM)}

Irritable bowel syndrome with diarrhea was assumed as a type of diarrhea, and values were set with reference to findings from the 1950s, using colorectal contrast, continuously observed without using antispasmodic agent (Figure 2C). ${ }^{14}$ Namely, in addition to the 7 sphincters, it was assumed that there were a total of 15 narrow lumen, their calibers were set to $0.5 \mathrm{~cm}$, similar to the sphincter. The different calibers were set as follows: the radius of the cecum was set to 2.5 $\mathrm{cm}$, the radius of the ascending colon was set to $2 \mathrm{~cm}$, the radius of the transverse colon was set to $1.5 \mathrm{~cm}$, the radius of the descending colon and the sigmoid colon were set to $1.2 \mathrm{~cm}$, and the radius of the rectum was set to $2 \mathrm{~cm}$. Gravity and density were assumed to be equal to that of the VHM.

In order to clarify the velocity change according to the size of the lumen, each of the velocities were compared in VHM, VCM, and VDM under the cecal pressure of $80 \mathrm{mmHg}$ and flow volume of $1 \mathrm{~mL} \mathrm{~s}^{-1}$. In addition, comparison of the CTT in the VHM, VCM, and VDM were calculated, giving the range of cecal flow volume as 0.1 to $1 \mathrm{~mL} \mathrm{~s}^{-1}$.

In the normal form of the large intestine, is the change in pressure obtained by inflow volume similar to HAPC?

In the VHM, inflow volume was set to $1 \mathrm{~mL} \mathrm{~s}^{-1}$, cecal pressure was varied (20-80 $\mathrm{mmHg}$ ), and the pressures transmitted distally were calculated. Finally, whether or not the connected pressure data was similar to that of HAPC was investigated.

\section{Results}

\section{CTT depends on caliber, cecum inflow} volume, fluid density, fluid velocity, and gravity, and constipation and diarrhea are determined by Bernoulli's principle Comparison of velocity in VHM, VCM, and VDM

A high-velocity spike was noted at the sphincter site in the VHM (Figure 3). In the VCM, the velocity was very slow due to the wide lumen. In the VDM, the high velocity spike occurred more frequently than the VHM, and the velocity of the baseline increased due to a narrow caliber.

\section{Comparison of CTT in VHM, VCM, and VDM}

Among the 4 sections: 1) cecum and ascending colon; 2) transverse colon; 3) descending colon; and 4) sigmoid colon and rectum, the CTT of VCM was long at any site and was short at VDM (Figure 4). Furthermore, the descending colon had the shortest time among all the models. 
A

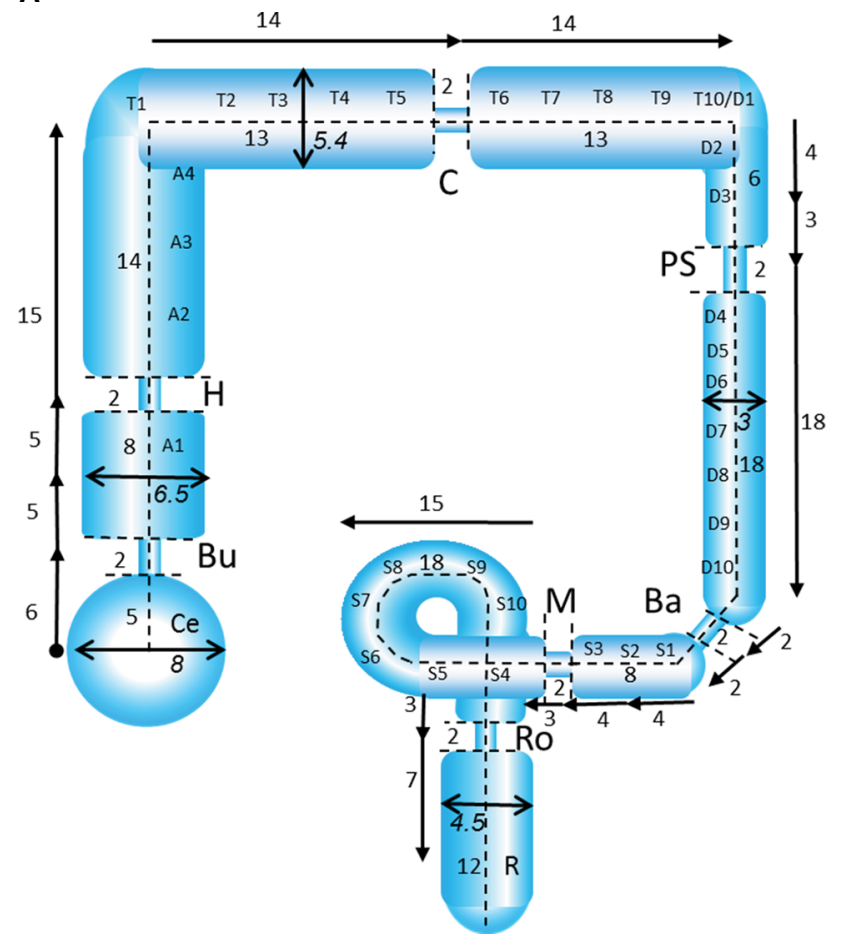

B

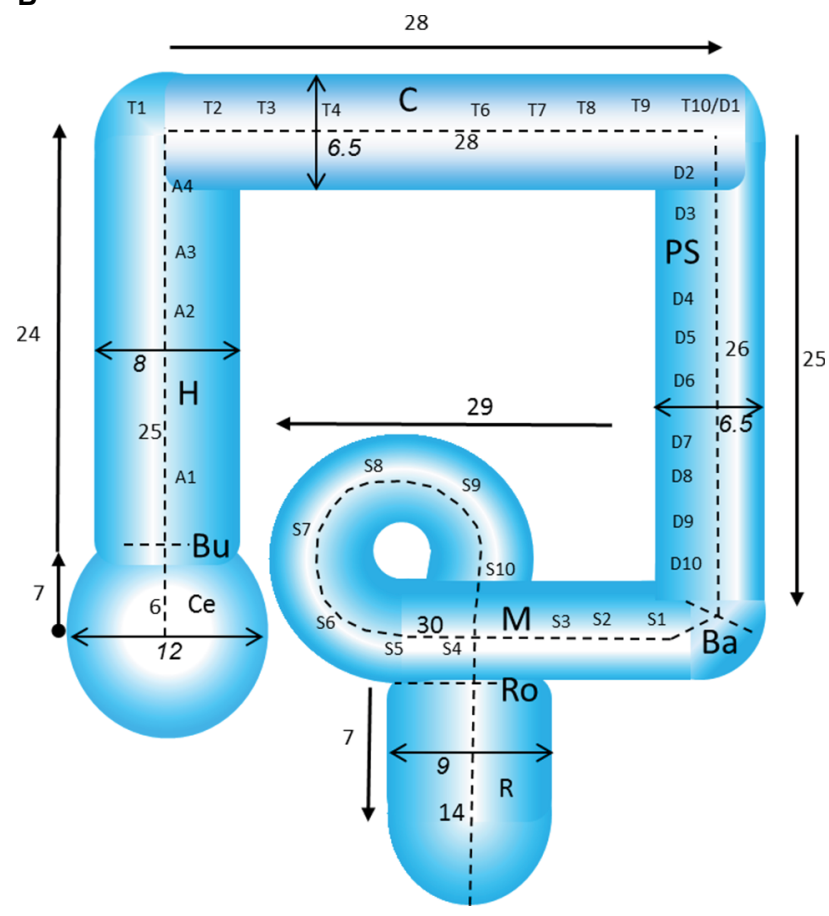

C

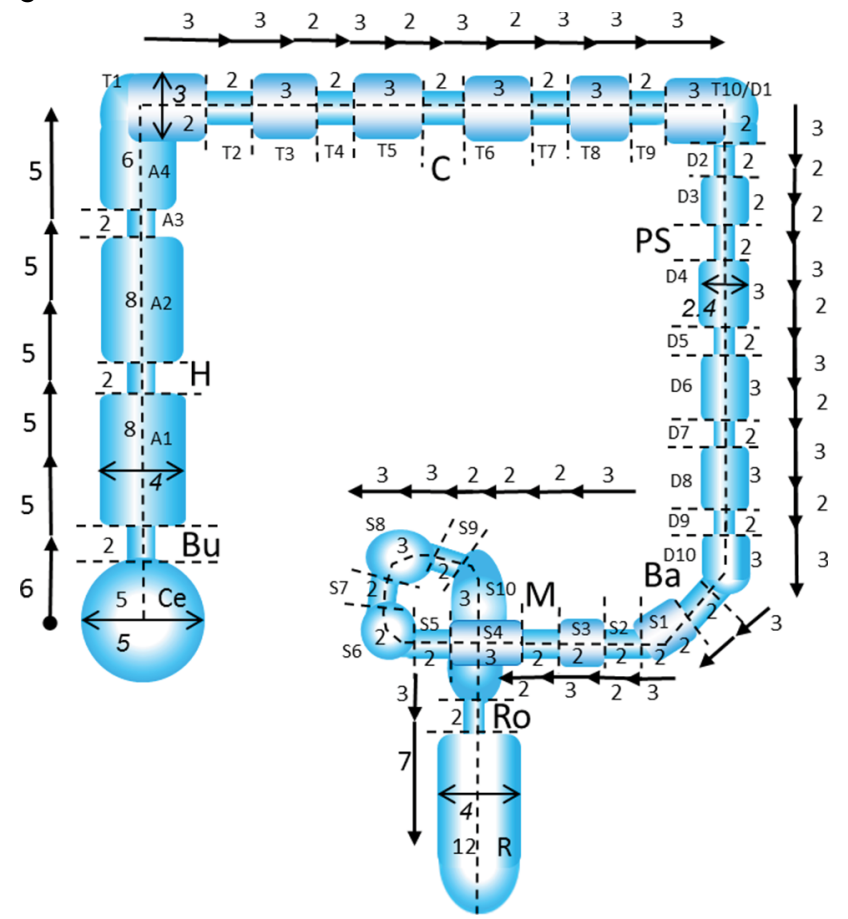

Figure 2 Setting of caliber and length.

Notes: (A) Setting of caliber and length of virtual healthy model: narrow calibers due to the sphincters were set. (B) Setting of caliber and length of virtual constipation model. (C) Setting of caliber and length of virtual diarrhea model. All lengths are given in centimeters. Italic type indicates the diameter. The number on arrow lines is the length for calculation of velocity and pressure. The number on broken lines is the length for calculation of CTT.

Abbreviations: Ba, Balli ring; Bu, Busi ring; C, Cannon ring; Ce, cecum; CTT, colonic transit time; H, Hirsch ring; M, Moultier ring; PS, Payr-Strauss ring; R, rectum; Ro, Rossi ring.

\section{Inflow volume and CTT due to difference in caliber}

The CTT and inflow volume were inversely proportional to the model with the same caliber.
$\mathrm{T} Q=$ Constant

$\mathrm{T}=\mathrm{CTT}, \mathrm{Q}=$ Flow volume

Compared to the VHM, the curve of the VCM was steep, and the curve of the VDM was gentle (Figure 5). Even with 

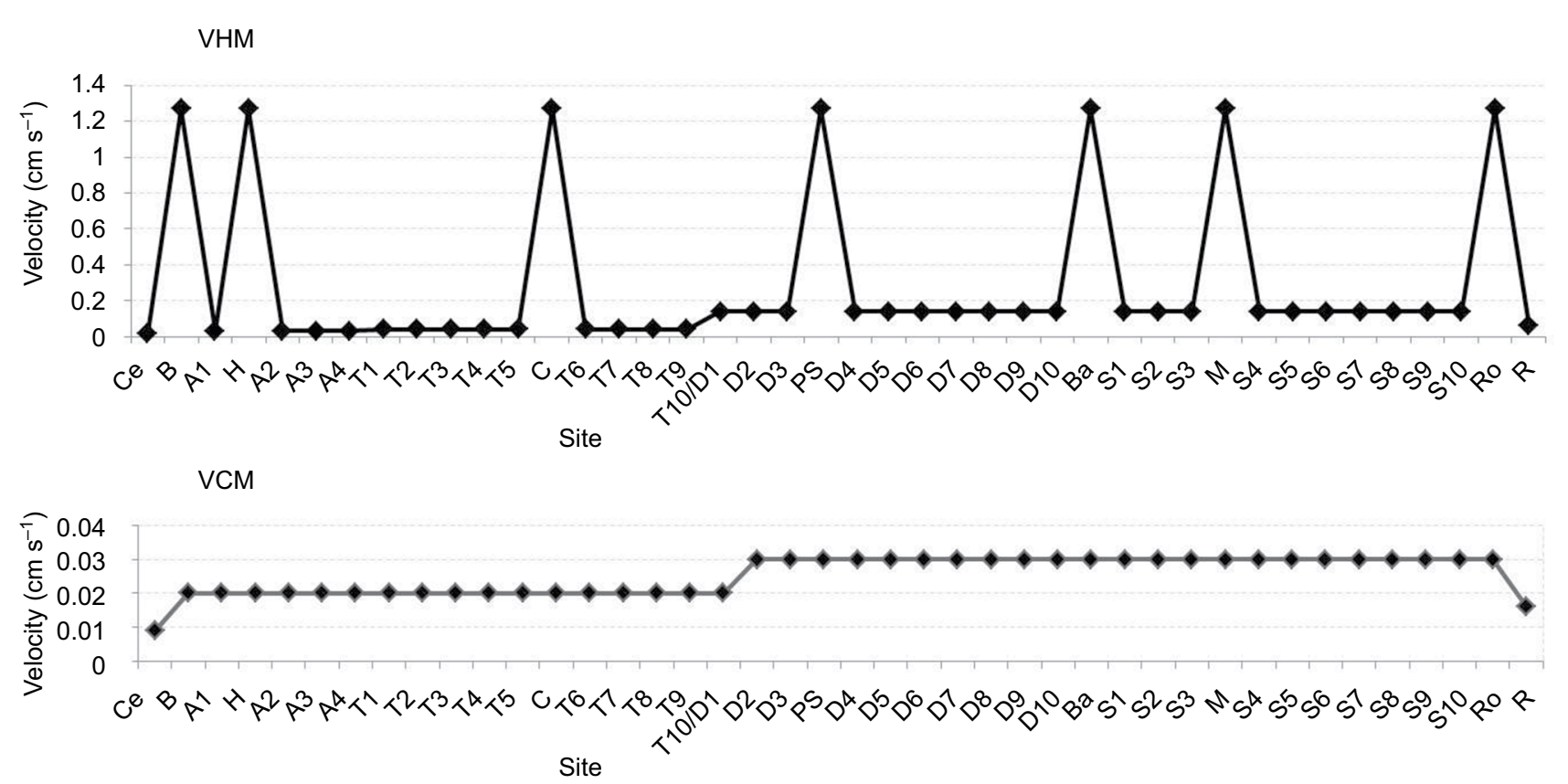

VDM

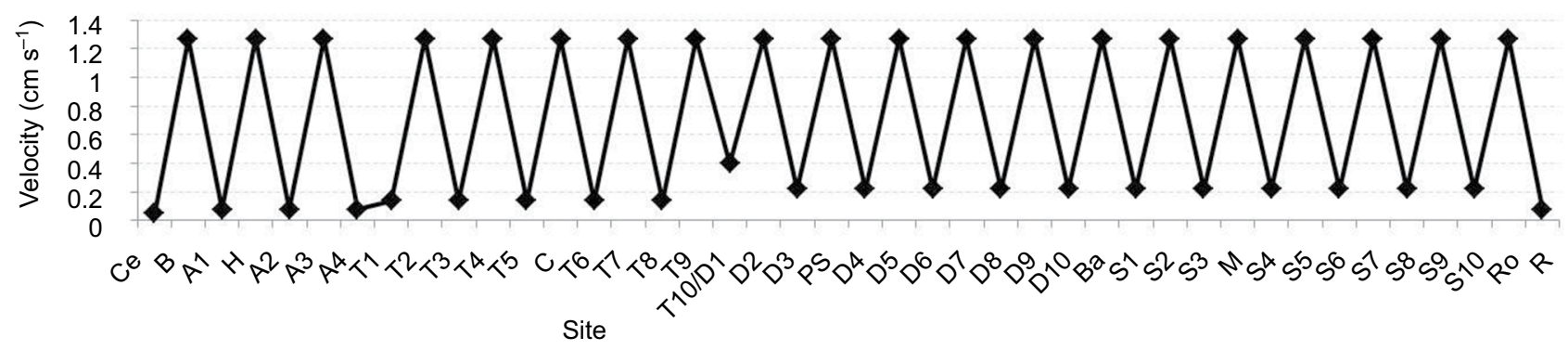

Figure 3 Comparison of the velocity in the VHM, VCM, and VDM.

Note: In the VCM, the unit of velocity differed by 2 digits.

Abbreviations: VCM, virtual constipation model; VDM, virtual diarrhea model; VHM, virtual healthy model.

the same flow volume as the VHM, the CTT was longer in the VCM and the CTT was shortened in the VDM. It was suggested that more flow volume is needed to shorten the CTT in the VCM. For example, to obtain a CTT equivalent to $0.1 \mathrm{~mL} \mathrm{~s}^{-1}\left(360 \mathrm{~mL} \mathrm{~h}^{-1}\right)$ in the VHM, a flow volume of 3 times $\left(0.3 \mathrm{~mL} \mathrm{~s}^{-1}=1080 \mathrm{~mL} \mathrm{~h}^{-1}\right)$ is required for the VCM.

\section{In the VHM, the change in pressure obtained by inflow volume is similar to HAPC}

The pressure from the cecum to the ascending colon, within the lumen, was reduced by gravity (Figure 6). In the transverse colon, the pressure change was slight; however, it increased sharply in the descending colon. When the cecal pressure was $20 \mathrm{mmHg}$, it became zero in the transverse colon. However, in the descending colon, it became positive pressure again, which persisted in the sigmoid colon and the rectum.

From the above, the following results were obtained.
- The velocity and the CTT varied depending on the diameter of the lumen and the inflow volume to the cecum.

- A high velocity spike occurs at the sphincter lumen, and as the number of narrow lumens of similar caliber increases, the overall velocity increases by these spikes.

- Even if the cecum velocity was low, the velocity increased with the flow volume. However, the velocity was decreased at the rectum.

- Changes in the transit time of diarrhea and constipation can be explained by flow dynamics.

- Based on Bernoulli's principle, intestinal pressure changed due to changes in lumen diameter and gravity.

- The calculated intestinal pressure values were similar to the HAPC of standing healthy people due to the contraction of the physiological sphincter and gravity.

- When the internal pressure of the cecum was $20 \mathrm{mmHg}$ or less, continuous positive pressure disappeared in the transverse colon, and positive pressure was observed from the descending colon, due to gravity. 


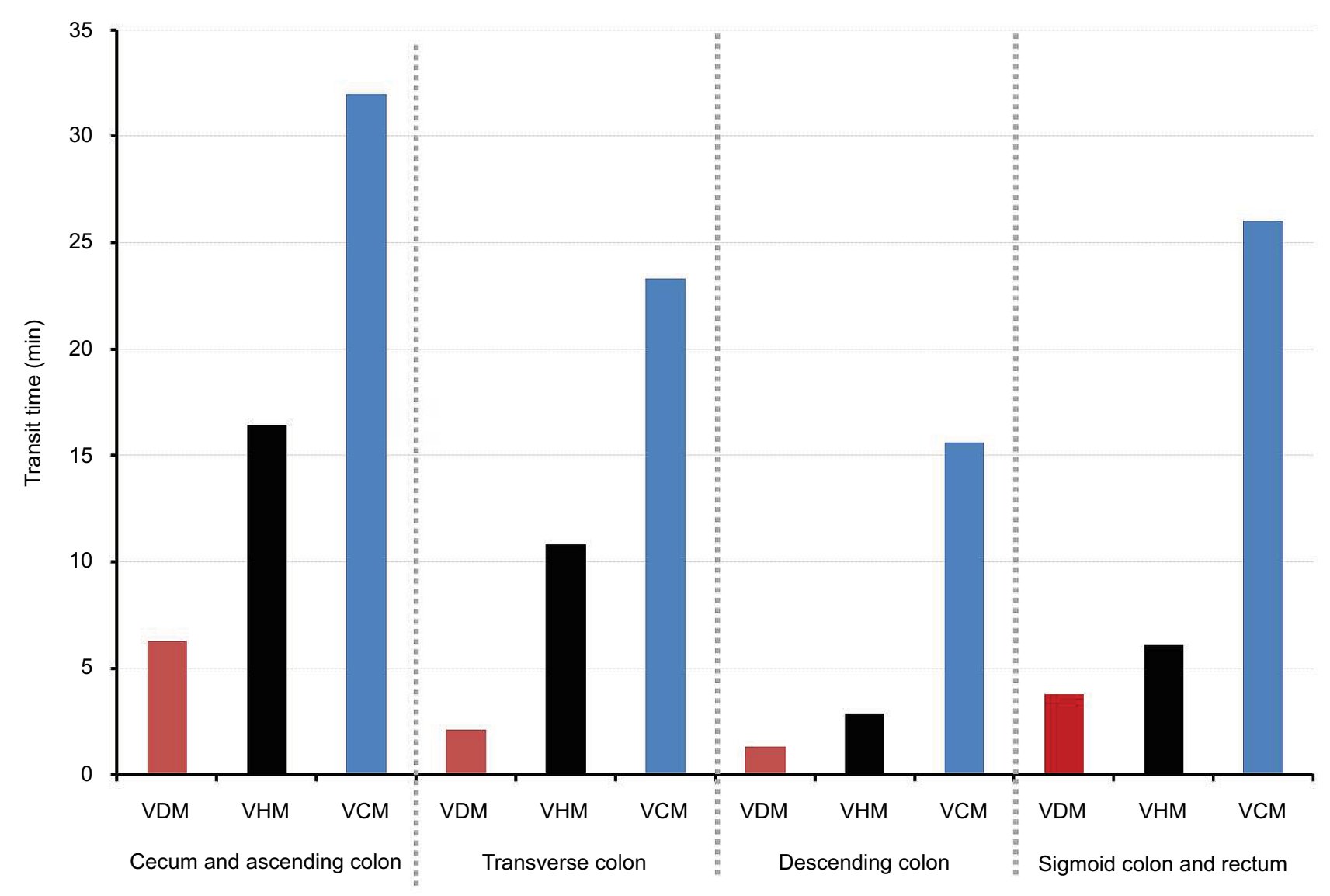

Figure 4 Comparison of transit times in each model.

Note: Results with bolus flow volume $\left(\mathrm{I} \mathrm{mL} \mathrm{s}^{-1}\right)$

Abbreviations: VCM, virtual constipation model; VDM, virtual diarrhea model; VHM, virtual healthy model.

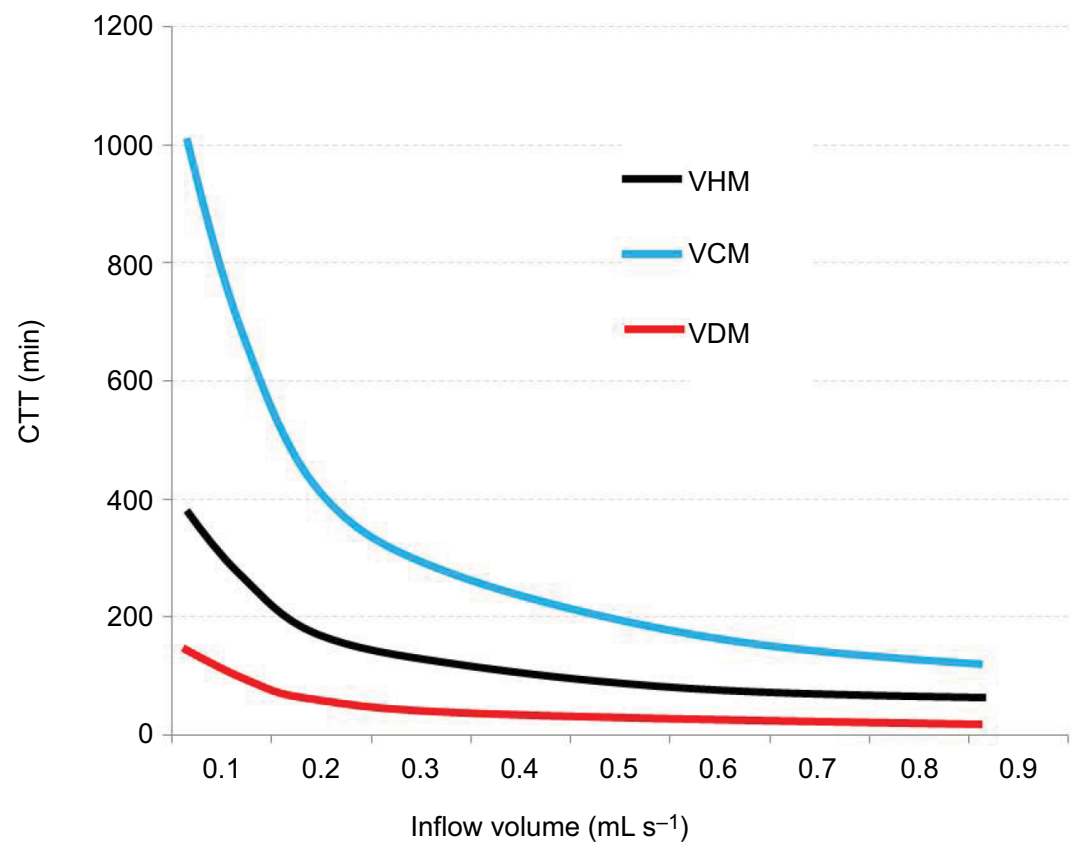

Figure 5 Inflow volume and CTT in the VHM, VCM, and VDM.

Abbreviations: CTT, colonic transit time; VCM, virtual constipation model; VDM, virtual diarrhea model; VHM, virtual healthy model. 


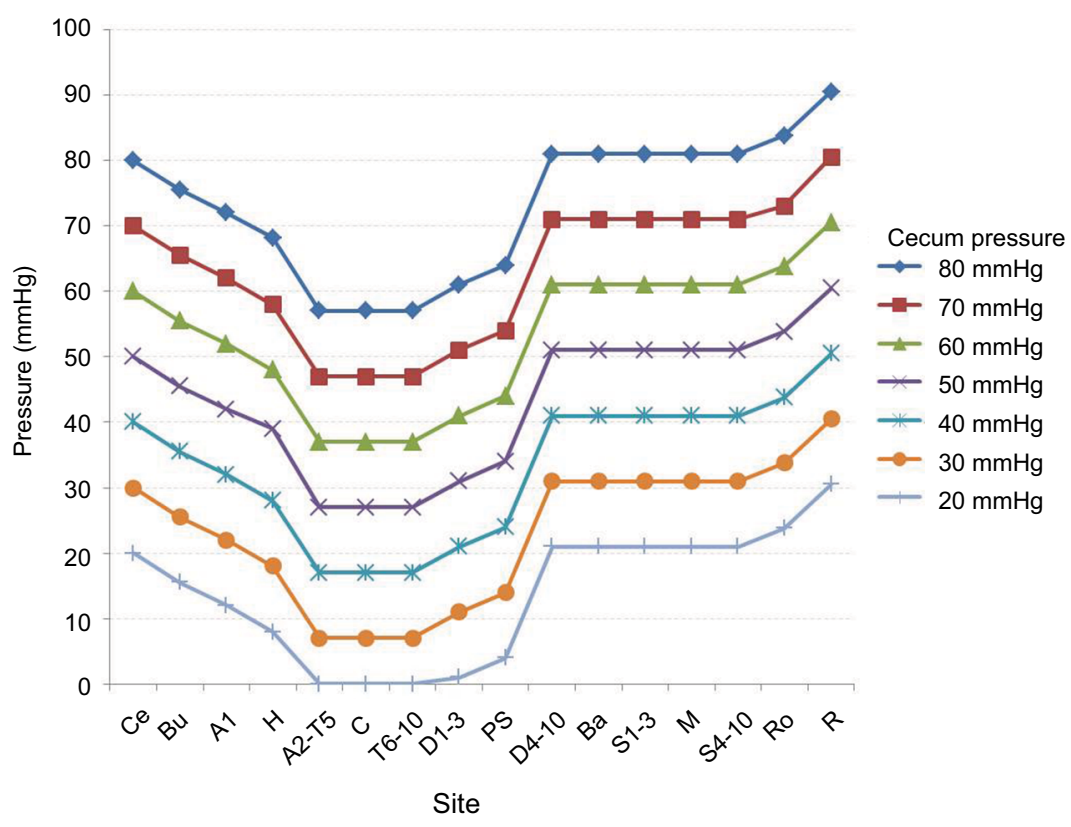

Figure 6 The relationship between cecal pressure $(20-80 \mathrm{mmHg})$ and pressure changes at each site.

\section{Discussion}

The empty colon has no motor activity. ${ }^{15}$ The myogenic control is exerted by oscillation of the smooth muscle membrane potential that occurs by stretching of the smooth muscle. ${ }^{16}$ The degree of this myogenic control can vary independently along the length and circumference of the gut wall. ${ }^{16}$ Contractions that strongly occlude the lumen and propagate are effective in producing rapid propulsion in the direction of propagation of the contraction. ${ }^{16}$ Such movement may occur in a narrow lumen with contraction. However, will it occur in a wide lumen, with a weak contractile force in the colon? Increasing of inflow volume of the colon can stretch smooth muscle; however, the contraction force caused by the expansion is affected by the compliance of the colon wall. For example, in megacolon, where intestinal wall compliance is large, even the intestinal tract expands, meaning that effective pressure cannot be obtained: the volume at the same pressure increases compared to healthy subjects. ${ }^{11}$ However, even in patients with advanced colon failure (Hirschsprung's disease, Ogilvie's syndrome, chronic intestinal pseudo-obstruction, and megacolon) who do not respond to pharmacologic stimulation, there is evidence that ACE from cecostomy provides adequate defecation. ${ }^{17-20}$ This fact suggests that the factor of flow volume to the cecum can affect CTT. Namely, when fluid flows into the cecum, colon motor activity may be influenced not only by the contraction force and compliance of smooth muscle, but also by fluid dynamics. In the closed colon of experimental animals intraluminal pressure is increased according to peristaltic contractions. ${ }^{15}$ Pressure increase due to such contraction can be physically explained by Laplace's law. However, in a living human without ileus, if another physical involvement within the colon is considered, because the colon is a long non-occluded space, Bernoulli's principle rather than Laplace's law should be applied. Recently, the author described the influence of Bernoulli's principle in colon diverticular disease, ${ }^{21}$ obstructive colitis, ${ }^{22}$ and irritable bowel syndrome. ${ }^{23}$ These studies were informative in deducing that in vivo, in the large intestine lumen, which is a continuous tube of physiological stenosis and dilation, the substance can move according to flow dynamics. For this reason, in the present study, a virtual model of the large intestine was set, and it was investigated whether or not Bernoulli's principle can be applied to constipation and diarrhea.

Colorectal movement is regulated by smooth muscle cells, interstitial cells of Cajal, Meissner's plexus, Auerbach's plexus, superior and inferior mesenteric nerve plexuses, and the parasympathetic nervous system. ${ }^{24,25}$ However, there are phenomena in colonic movement that cannot be explained by such nervous system control, for example, giant migrating contractions and HAPC. The details regarding their transmission are still unknown. ${ }^{2,5}$ Although it is known that the velocity of colonic contents decreases in the ascending colon, and increases from the descending colon to the sigmoid colon, ${ }^{5,6}$ the physiological reasons for this have not been elucidated. Some studies of normal subjects, measured using a wireless capsule (SmartPill), showed that the pressure was $60-80 \mathrm{mmHg}$ in the cecum, which decreased to 
20-40 $\mathrm{mmHg}$ in the central part of the large intestine, and then increased to $60-100 \mathrm{mmHg}$ at the proximity of the rectum. ${ }^{26-29}$ Furthermore, this pressure fluctuation was very similar to the propagation data of high-amplitude propagating sequences, measured by the manometer in a healthy person. ${ }^{30}$ As shown in this study, such pressure fluctuations can be explained by positional energy due to the involvement of gravity. It is known that in conditions of zero gravity in space, the peak defecation activity that occurs due to waking and diet, decreases. ${ }^{31}$ It is also known that intestinal peristalsis decreases due to head-down bed rest, ${ }^{32}$ and there is evidence for the involvement of intestinal motility due to gravity.

In healthy humans, colonic motility exhibits multimodal rhythms over a periodicity that is close to 24 hours, with peak activity occurring in the morning after waking and following meals. In addition, both propagating and non-propagating motor activity of the colon are suppressed at night. ${ }^{33-36}$ Within 1-3 minutes of the initial bite of a meal, segmental contractions begin in the proximal and distal colon. ${ }^{37}$ Characteristic movement in the human colon, was thought to be: "reverse peristalsis" in the ascending colon, "pendular movements" in the transverse colon, and "mass peristalsis" in the descending colon. ${ }^{38}$ Gastrocolic reflex (GCR) was described in 1979 as "gastrocolic response" by Snape et al. ${ }^{39}$ They explained that this response was an increase in distal colon motor activity related to food intake. In a whole colon manometric study in 1989, GCR was observed in both the proximal and distal colon, but the response of the descending colon to eating was the most intense. ${ }^{40}$ In addition, GCR in the proximal colon increased early on, and was short-lived, but in the distal colon, there was a more sustained increase. ${ }^{41}$ GCR in the proximal colon is believed to be due to the stimulation of stomach dilatation, as a result of ingestion of food, that has reached the medulla oblongata via the vagus nerve, and then gone from the spinal cord to the pelvic splanchnic nerve. ${ }^{38}$ However, this theory is doubtful, as reactions like gastrocolic reflex occur even in spinal cord injured patients who block this pathway. ${ }^{42}$ Furthermore, even with spinal cord injury, it is possible to immediately induce defecation by ACE. ${ }^{43,44}$ For example, in ACE by polyethylene glycol (PEG) after cecostomy, the mean toilet-sitting time was $51.7 \pm 3.5 \mathrm{~min}$ utes (range 10-180 minutes), with a mean irrigation dose of $847 \pm 55 \mathrm{~mL}(23 \pm 0.7 \mathrm{~mL} / \mathrm{kg}){ }^{45}$ For that reason, to examine the hypothesis of the pressure change in this study, the flow volume to the cecum was set at $1 \mathrm{~mL} \mathrm{~s}^{-1}\left(60 \mathrm{~mL} \mathrm{~min}^{-1}\right)$, an amount that is consistent with gravity-infused ACE.

Mass movement is synonymous with mass peristalsis, and the relationship with HAPC was found using a pressure measurement experiment. ${ }^{5}$ The characteristics of HAPC are as follows 2 : 1) occur spontaneously in response to pharmacological agents or colonic distention, 2) increase upon awakening, 3) are much more common during the day, 4) increase after meals, 5) a majority originate in the proximal colon; most do not propagate beyond the midcolon, and fewer than $5 \%$ reach the rectum, 6) can transfer colonic contents over long distances, 7) can be associated with internal anal sphincter relaxation, 8) are reduced in slow transit constipation and increased in diarrhea-predominant irritable bowel syndrome, and may explain disturbances of colonic transit in these conditions. Namely, changes in the propagation pressure that were calculated by the inflow amount of the cecum in this study, did not contradict the results of HAPC characteristics found in the previous report.

In the research of Bouchoucha et al, ${ }^{46}$ the determination of segmental CTT divided the colon into 3 parts: the "right colon" (cecum, ascending colon, hepatic flexure, right part of the transverse colon), the "left colon" (left part of the transverse colon, splenic flexure, descending colon), and the "terminal intestine" (sigmoid, rectum). Schematically, this division corresponds to the embryologic origin of the colon and its neural, vascular, and lymphatic correspondents, and to the physiological functions of these segments. The "right colon" is of mid-gut embryological origin, and has a predominant function in the absorption of water, sodium, and chloride, and microbiota metabolism. The major part of the "left colon" is of hind-gut embryological origin, and its main function is the transfer of feces. Finally, the "terminal intestine" plays a major role in defecation. Differences in the function of the left and right colon, as described above, may be due to the lower mobility of the right colon compared to the left. However, in vitro, smooth muscles of the human colon electrophysiology and mechanical characteristics showed no obvious difference between the right and left colon. ${ }^{47}$ For these reasons, the colon was regarded as a simple luminal organ, and the pure influence of colonic fluid dynamics was assessed. As a result of this study, it can be explained that the difference in the movement and function between the right and left colon is caused by a change in intestinal pressure and velocity due to the influence of fluid dynamics.

Corsetti et al reported that low-amplitude propagating sequences (LAPS) and pan-colonic pressurizations (PCP) were confirmed using new high-resolution colonic motor records. ${ }^{48}$ LAPS were both anterograde and retrograde; PCP were associated with relaxation of the anal sphincter and the simultaneous pressure rise in all colon regions; it is possible to explain these by pressure propagation of flow dynamics. 
When the cecal pressure is low, there is a possibility that LAPS may occur, due to which positive pressure disappears during transmission (theoretically, when the cecal pressure is $20 \mathrm{mmHg}$ or less, it becomes negative pressure in the transverse colon). In addition, even the movement inside the lumen is quiescent due to release of the anal sphincter, which can be explained by pressure rise that occurs in the entire intestinal tract due to induction of flow dynamics movement, resulting in PCP.

The results of this study may bring about a debate regarding the clinical practice of gastroenterology. Even if 1000 $2000 \mathrm{~mL}$ of water flows from the small intestine to the cecum in a healthy subject, it is absorbed in the large intestine, and the fecal water content is reduced to $100-200 \mathrm{~mL}^{49,50}$ Therefore, water is absorbed in each segment of the large intestine. If the inflow amount decreases, the CTT will be extended, compared to the calculated result in this study. However, it is inferred that the relationship between the flow volume and CTT is the result of (Figure 5) substances that could be reduced by absorption, such as PEG. ${ }^{51}$ During saline lavage, fluid absorption of $2400-3200 \mathrm{~mL}$ could be expected, while $4000 \mathrm{~mL}$ of PEG would be expected to result in the absorption of only $190-250 \mathrm{~mL}$ over 3-4 hours of consumption. ${ }^{51}$ Namely, in the case of peroral ingestion of PEG, from the results shown in Figure 5, if total gut transit time, including the times of stomach and small intestine, the total time of whole gut cleaning is calculated to be about 4 hours when ingested at $0.2 \mathrm{~mL} \mathrm{~s}^{-1}\left(720 \mathrm{~mL} \mathrm{~h}^{-1}\right)$. This is not inconsistent with real clinical evidence. In the study of colonoscopy preparation, subjects given $4000 \mathrm{~mL}$ of PEG had a cleaning effect similar to subjects who were given $20 \mathrm{mg}$ of bisacodyl, added to 2000 $\mathrm{mL}$ of PEG. ${ }^{52}$ As bisacodyl can induce HAPC ${ }^{53}$ it is evidence that increasing the non-absorbing liquid could have the same function as bisacodyl. Interestingly, $2000 \mathrm{~mL}$ of PEG plus bisacodyl was not superior to $4000 \mathrm{~mL}$ PEG for bowel cleansing for colonoscopy in patients with chronic constipation. ${ }^{54}$ This evidence suggests the usefulness of treatment of increasing the amount of fluid in chronic constipation. Indeed, there are many reports showing the effectiveness of PEG in chronic constipation in children, adults, and the elderly. ${ }^{55-57}$ In addition, not only the velocity of inflow, but also the total amount due to the inflow duration, influences the water absorption capacity in the large intestine. In the case of constipation without mega colon, the velocity increases as the inflow volume increases, so if VHM in this study causes constipation by low water content, lubiprostone ${ }^{58}$ and linaclotide, ${ }^{59}$ which increase the amount of fluid in the gastrointestinal tract, can cause a decrease in the CTT. However, differences in luminal diameter may be influenced not only by flow dynamics, but also by absorbable colonic mucosa surface area. Namely, in the case of chronic constipation with megacolon, the effect of laxatives in which increasing water content, may be limited by reabsorbed water. Ischemic colitis has been reported as a side effect of both stimulant laxatives ${ }^{60}$ and antidiarrheal drugs, ${ }^{61,62}$ but its mechanism is unknown. This enigma can be explained by Bernoulli's principle because there is development of ischemia of the intestinal tract when the difference between the lumen with a wide caliber and narrow bore is large..$^{22}$ In a colon with a narrow colonic lumen, partial rapid expansion with antidiarrheal drugs could cause partial highpressure. Also, in the dilated colon, a partial strong contraction brought on by laxatives could cause high-pressure due to partial expansion of its proximal lumen. In addition, when many fermentations occur in the right colon, the gas build-up from fermentation reduces the velocity of movement in the right colon; as there is no positional energy in gas, a large quantity of gas can accumulate in the transverse colon. Therefore, a large amount of gas is an important problem to be solved for constipation therapy.

This study has many limitations, as indicated in the "Methods". Several critical physiological features of relevance were ignored in order to test the hypothesis. In addition, stool properties other than stool density in the three models (VCM, VDM, and VHM) were not considered, including salt concentration, $\mathrm{pH}$ variation, as well as their simulative factors associated with microbiota and cytokines/hormones, and their interaction with colonic epithelial and smooth muscle layers. However, the functional significance of "control" could become clearer by elucidating the basic movement.

\section{Disclosure}

The author reports no conflicts of interest in this work.

\section{References}

1. Lam C, Chaddock G, Marciani Laurea L, et al. Distinct abnormalities of small bowel and regional colonic volumes in subtypes of irritable bowel syndrome revealed by MRI. Am J Gastroenterol. 2017;112(2):346-355.

2. Bharucha AE. High amplitude propagated contractions. Neurogastroenterol Motil. 2012;24(11):977-982.

3. Bassotti G, Gaburri M, Imbimbo BP, Morelli A, Whitehead WE. Distension-stimulated propagated contractions in human colon. Dig Dis Sci. 1994;39(9):1955-1960.

4. Sasaki Y, Hada R, Nakajima H, Munakata A. Difficulty in estimating localized bowel contraction by colonic manometry: a simultaneous recording of intraluminal pressure and luminal caliber. Neurogastroenterol Motil. 1996;8(3):247-253.

5. Cook IJ, Furukawa Y, Panagopoulos V, Collins PJ, Dent J. Relationships between spatial patterns of colonic pressure and individual movements of content. Am J Physiol Gastrointest Liver Physiol. 2000;278(2):G329-G341. 
6. Hiroz P, Schlageter V, Givel JC, Kucera P. Colonic movements in healthy subjects as monitored by a Magnet Tracking System. Neurogastroenterol Motil. 2009;21(8):e838-e857.

7. Balli R. The sphincters of the colon. Radiology. 1939;33(3):372-376.

8. Gregersen T, Haase AM, Schlageter V, Gronbaek H, Krogh K. Regional gastrointestinal transit times in patients with carcinoid diarrhea: assessment with the novel 3D-transit system. J Neurogastroenterol Motil. 2015;21(3):423-432.

9. Rodriguez L, Nurko S, Flores A. Factors associated with successful decrease and discontinuation of antegrade continence enemas (ACE) in children with defecation disorders: a study evaluating the effect of ACE on colon motility. Neurogastroenterol Motil. 2013;25(2):e140-e181.

10. Patriquin H, Martelli H, Devroede G. Barium enema in chronic constipation: is it meaningful? Gastroenterology. 1978;75(4):619-622.

11. O’Dwyer RH, Acosta A, Camilleri M, Burton D, Busciglio I, Bharucha AE. Clinical features and colonic motor disturbances in chronic megacolon in adults. Dig Dis Sci. 2015;60(8):2398-2407.

12. Knudsen K, Fedorova TD, Bekker AC, et al. Objective colonic dysfunction is far more prevalent than subjective constipation in Parkinson's disease: a colon transit and volume study. J Parkinsons Dis. 2017;7(2):359-367.

13. Lam C, Chaddock G, Marciani L, et al. Colonic response to laxative ingestion as assessed by MRI differs in constipated irritable bowel syndrome compared to functional constipation. Neurogastroenterol Motil. 2016;28(6):861-870.

14. Mastunaga F. Radiography of the Large Intestine-Based on Dynamic Observation. Tokyo: Igaku Syoin Ltd; 1958:37-42. Japanese [with English abstract].

15. Costa M, Dodds KN, Wiklendt L, Spencer NJ, Brookes SJ, Dinning PG. Neurogenic and myogenic motor activity in the colon of the guinea pig, mouse, rabbit, and rat. Am J Physiol Gastrointest Liver Physiol. 2013; 305(10):G749-G759.

16. Sana SK. Colonic motor activity. Surg Clin North Am. 1993;73(6): 1201-1223.

17. Rivera MT, Kugathasan S, Berger W, Werlin SL. Percutaneous colonoscopic cecostomy for management of chronic constipation in children. Gastrointest Endosc. 2001;53(2):225-228.

18. Peeraully MR, Lopes J, Wright A, et al. Experience of the MACE procedure at a regional pediatric surgical unit: a 15-year retrospective review. Eur J Pediatr Surg. 2014;24(1):113-116.

19. Hanauer SB, Wald A. Acute and chronic megacolon. Curr Treat Options Gastroenterol. 2007;10(3):237-247.

20. Uno Y. Introducer method of percutaneous endoscopic cecostomy and antegrade continence enema by use of the Chait Trapdoor cecostomy catheter in patients with adult neurogenic bowel. Gastrointest Endosc. 2006;63(4):666-673.

21. Uno Y, van Velkinburgh JC. Logical hypothesis: low FODMAP diet to prevent diverticulitis. World J Gastrointest Pharmacol Ther. 2016;7(4):503-512

22. Uno Y. Management of colon stents based on Bernoulli's principle. Indian J Gastroenterol. 2017;36(2):69-74.

23. Uno Y. Enigma of intestinal gas in irritable bowel syndrome. Am J Gastroenterol. 2017;112(7):1166-1167.

24. Furness JB, Callaghan BP, Rivera LR, Cho HJ. The enteric nervous system and gastrointestinal innervation: integrated local and central control. Adv Exp Med Biol. 2014;817:39-71.

25. Sanders KM, Ward SM, Koh SD. Interstitial cells: regulators of smooth muscle function. Physiol Rev. 2014;94(3):859-907.

26. Hasler WL, Saad RJ, Rao SS, et al. Heightened colon motor activity measured by a wireless capsule in patients with constipation: relation to colon transit and IBS. Am J Physiol Gastrointest Liver Physiol. 2009;297(6):G1107-G1114.

27. Saad RJ, Hasler WL. A technical review and clinical assessment of the wireless motility capsule. Gastroenterol Hepatol (N Y). 2011;7(12):795-804.

28. Tran K, Brun R, Kuo B. Evaluation of regional and whole gut motility using the wireless motility capsule: relevance in clinical practice. Therap Adv Gastroenterol. 2012;5(4):249-260.
29. Sequeira IR, Lentle RG, Kruger MC, Hurst RD. Assessment of the effect of intestinal permeability probes (lactulose and mannitol) and other liquids on digest a residence times in various segments of the gut determined by wireless motility capsule: a randomised controlled trial. PLoS One. 2015;10:e0143690.

30. Dinning PG, Benninga MA, Southwell BR, Scott SM. Paediatric and adult colonic manometry: a tool to help unravel the pathophysiology of constipation. World J Gastroenterol. 2010;16(41):5162-5172.

31. Liang X, Zhang L, Wan Y, et al. Changes in the diurnal rhythms during a 45-day head-down bed rest. PLoS One. 2012;7(10):e47984.

32. Iovino P, Chiarioni G, Bilancio G, et al. New onset of constipation during long-term physical inactivity: a proof-of-concept study on the immobility-induced bowel changes. PLoS One. 2013;8(8):e72608.

33. Rao SS, Sadeghi P, Beaty J, Kavlock R, Ackerson K. Ambulatory 24-h colonic manometry in healthy humans. Am J Physiol Gastrointest Liver Physiol. 2001;280(4):G629-G639.

34. Bampton PA, Dinning PG, Kennedy ML, Lubowski DZ, Cook IJ. Prolonged mulipoint recording of colonic manometry in the unprepared human colon - Providing insight into potentially relevant pressure wave parameters. Am J Gastroenterol. 2001;96(6):1838-1848.

35. Dinning PG, Smith TK, Scott SM. Pathophysiology of colonic causes of chronic constipation. Neurogastroenterol Motil. 2009;21(Suppl 2):20-30.

36. Roarty TP, Suratt PM, Hellmann P, McCallum RW. Colonic motor activity in women during sleep. Sleep. 1998;21(3):285-288.

37. Szmulowicz UM, Hull TL. Colonic Physiology. Beck DE et al, editors. The ASCRS Textbook of Colon and Rectal Surgery. Second edition. NY, USA: Springer Science + Business Media LLC; 2011:23-39.

38. Netter FH. The Netter Collection of Medical Illustrations: Digestive System: Part II - Lower Digestive Tract Vol 3. Elsevier; 2006:86-87.

39. Snape WJ Jr, Wright SH, Battle WM, Cohen S. The gastrocolic response: evidence for a neural mechanism. Gastroenterology. 1979;77(6):1235-1240.

40. Moreno-Osset E, Bazzocchi G, Lo S, et al. Association between postprandial changes in colonic intraluminal pressure and transit. Gastroenterology. 1989;96(5 Pt 1):1265-1273.

41. Bassotti G, Betti C, Imbimbo BP, Pelli MA, Morelli A. Colonic motor response to eating: a manometric investigation in proximal and distal portions of the viscus in man. Am J Gastroenterol. 1989;84(2):118-122.

42. Suttor VP, Ng C, Rutkowski S, Hansen RD, Kellow JE, Malcolm A. Colorectal responses to distension and feeding in patients with spinal cord injury. Am J Physiol Gastrointest Liver Physiol. 2009;296(6):G1344-G1349.

43. Hughes M. Bowel management in spinal cord injury patients. Clin Colon Rectal Surg. 2014;27(3):113-115.

44. Yang CC, Stiens SA. Antegrade continence enema for the treatment of neurogenic constipation and fecal incontinence after spinal cord injury. Arch Phys Med Rehabil. 2000;81(5):683-685.

45. Siddiqui AA, Fishman SJ, Bauer SB, Nurko S. Long-term follow-up of patients after antegrade continence enema procedure. $J$ Pediatr Gastroenterol Nutr. 2011;52(5):574-580.

46. Bouchoucha M, Devroede G, Bon C, Raynaud JJ, Bejou B, Benamouzig R. How many segments are necessary to characterize delayed colonic transit time? Int J Colorectal Dis. 2015;30(10):1381-1389.

47. Choe EK, Moon JS, Moon SB, So IS, Park KJ. Electromechanical characteristics of the human colon in vitro: is there any difference between the right and left colon? Int J Colorectal Dis. 2010;25(9):1117-1126.

48. Corsetti M, Pagliaro G, Demedts I, et al. Pan-colonic pressurizations associated with relaxation of the anal sphincter in health and disease: a new colonic motor pattern identified using high-resolution manometry. Am J Gastroenterol. 2017;112(3):479-489.

49. Debongnie JC, Phillips SF. Capacity of the human colon to absorb fluid. Gastroenterology. 1978;74(4):698-703.

50. Ooms L. Alterations in intestinal fluid movement. Scand J Gastroenterol Suppl. 1983;84:65-77.

51. DiPalma JA, Brady CE 3rd. Colon cleansing for diagnostic and surgical procedures: polyethylene glycol-electrolyte lavage solution. $\mathrm{Am} \mathrm{J}$ Gastroenterol. 1989;84(9):1008-1016. 
52. Sharma VK, Chockalingham SK, Ugheoke EA, et al. Prospective, randomized, controlled comparison of the use of polyethylene glycol electrolyte lavage solution in four-liter versus two-liter volumes and pretreatment with either magnesium citrate or bisacodyl for colonoscopy preparation. Gastrointest Endosc. 1998;47(2):167-171.

53. Hamid SA, Di Lorenzo C, Reddy SN, Flores AF, Hyman PE. Bisacodyl and high-amplitude-propagating colonic contractions in children. J Pediatr Gastroenterol Nutr. 1998;27(4):398-402.

54. Parente F, Vailati C, Bargiggia S, et al. 2-Litre polyethylene glycolcitrate-simethicone plus bisacodyl versus 4-litre polyethylene glycol as preparation for colonoscopy in chronic constipation. Dig Liver Dis. 2015;47(10):857-863.

55. Treepongkaruna S, Simakachorn N, Pienvichit P, et al. A randomised, double-blind study of polyethylene glycol 4000 and lactulose in the treatment of constipation in children. BMC Pediatr. 2014;14:153.

56. Muenguez M, Lopez Higueras A, Júdez J. Use of polyethylene glycol in functional constipation and fecal impaction. Rev Esp Enferm Dig 2016;108(12):790-806.
57. Chassagne P, Ducrotte P, Garnier P, Mathiex-Fortunet H. Tolerance and long-term efficacy of polyethylene glycol $4000\left(\right.$ Forlax $\left.^{\circledR}\right)$ compared to lactulose in elderly patients with chronic constipation. J Nutr Health Aging. 2017;21(4):429-439.

58. Christie J, Shroff S, Shahnavaz N, et al. A randomized, double-blind, placebo-controlled trial to examine the effectiveness of lubiprostone on constipation symptoms and colon transit time in diabetic patients. $\mathrm{Am}$ J Gastroenterol. 2017;112(2):356-364.

59. Thomas RH, Allmond K. Linaclotide (Linzess) for irritable bowel syndrome with constipation and for chronic idiopathic constipation. P T. 2013;38(3):154-160.

60. Ajani S, Hurt RT, Teeters DA, Bellmore LR. Ischemic colitis associated with oral contraceptive and bisacodyl use. BMJ Case Rep. 2012;2012:bcr1220115451.

61. Friedel D, Thomas R, Fisher RS. Ischemic colitis during treatment with alosetron. Gastroenterology. 2001;120(2):557-560.

62. Gulstad MB, Thomsen H. [Ischaemic colitis after loperamide treatment]. Ugeskr Laeger. 2015;177(2A):84-85. Danish.
Clinical and Experimental Gastroenterology

\section{Publish your work in this journal}

Clinical and Experimental Gastroenterology is an international, peerreviewed, open access, online journal publishing original research, reports, editorials, reviews and commentaries on all aspects of gastroenterology in the clinic and laboratory. This journal is included on PubMed. The manuscript management system is completely online 